\title{
Combination Treatment of SGLT2 Inhibitors and GLP- 1 Receptor Agonists: Symbiotic Effects on Metabolism and Cardiorenal Risk
}

Edison Goncalves (D) David S. H. Bell

Received: January 21, 2018 / Published online: April 5, 2018

(C) The Author(s) 2018

\begin{abstract}
Introduction: When treating type 2 diabetes, drugs that cause hypoglycemia and weight gain should, if possible, be avoided. In addition, due to the increased incidence and prevalence of cardiovascular disease, cardiac events and heart failure, as well as the accelerated renal decompensation that may occur with type 2 diabetes, hypoglycemic agents that have the potential to lower cardiac and renal risk should be utilized as early as possible in the course of the disease.

Methods: This is a literature review of the efficacy of combined treatment with a glucagonlike peptide 1 (GLP-1) agonist and a sodium
\end{abstract}

Enhanced content To view enhanced content for this article go to https://doi.org/10.6084/m9.figshare. 6016016.

E. Goncalves $(\bowtie)$

Diabetes \& Thyroid Associates, 2022 Brookwood

Medical Center Dr, Birmingham 35209, AL, USA

e-mail: goncalves.edison@gmail.com

D. S. H. Bell

Southside Endocrinology, Irondale, AL, USA

D. S. H. Bell

University of Alabama at Birmingham, Birmingham, AL, USA glucose cotransporter-2 (SGLT2) inhibitor in lowering glycated hemoglobin (HbA1c) level, cardiac risk, cardiac events and renal decompensation.

Results: Evidence is presented which shows that the efficacy of combined SGLT2 inhibitor/GLP-1 receptor agonist therapy is additive in lowering HbA1c level, systolic blood pressure and body weight. This combined therapy also has the potential to cause further reductions in major cardiovascular events and renal decompensation than those achieved with either drug used as monotherapy or in combination with other hypoglycemic agents.

Conclusion: The combination of a GLP-1 agonist and an SGLT2-inhibitor has additive effects on lowering HbA1c and systolic blood pressure, body weight and cardiac risk and has the potential to synergistically reduce cardiovascular events and decelerate renal decompensation. A large prospective study of this combination is needed to prove that this synergism, especially as it applies to cardiac risk factors, cardiac events and mortality and preservation of renal function, is proven.

Keywords: Canagliflozin; Empagliflozin; GLP-1 receptor agonist; Heart failure; Liraglutide; Myocardial infarction; Renal decompensation; SGLT2 inhibitor; Stroke; Weight loss 


\section{INTRODUCTION}

In choosing drugs to treat type 2 diabetes, insulin and/or secretagogues are not a prudent initial choice because of their association with hypoglycemia and weight gain [1]. In addition to these limitations, drugs that cause weight gain have the potential to increase insulin resistance and/or cardiac risk. Drugs that lower body weight, such as glucagon-like peptide 1 (GLP-1) receptor agonists and sodium glucose cotransporter- 2 (SGLT2) inhibitors should be preferred. These drugs lead to significant cardiometabolic improvements, with a decrease in cardiac and skeletal muscle fat leading to improvement in insulin sensitivity. Furthermore, with a reduction in hepatic fat there is improved hepatic insulin sensitivity and a reduction in hepatic glucose production. Also, with a decrease in beta cell fat there is a deceleration of beta cell apoptosis that leads to improved insulin secretion [2,3]. Therefore, combined treatment with a GLP-1 receptor agonist and an SGLT2 inhibitor, with or without metformin, should be the preferred initial therapy for type 2 diabetes because in addition to lowering glucose levels, body fat will be reduced as will blood pressure and cardiac risk. With these changes there is the potential for a decrease in cardiac events, cardiac and total mortality and deceleration of the decline in renal function.

\section{METHODS}

We conducted a Medline search of the literature using the Boolean expression GLP-1 receptor agonist AND SGLT2 inhibitor, as well as using the individual drug names of both classes along with the modifier AND; looking for studies showing the effects of this combination in lowering glycated hemoglobin (HbA1c) level, body weight and cardiac risk factors. This study is based on previously conducted studies and does not contain any studies with human participants or animals performed by any of the authors.

\section{RESULTS}

We found only two prospective studies on of the combination of an SGLT2 inhibitor and GLP-1 agonist (Table 1). In the DURATION-8 study, combined therapy with dapagliflozin given once daily and the GLP-1 receptor agonist exenatide given once weekly was found to reduce $\mathrm{HbA} 1 \mathrm{c}$ by $2 \%$ accompanied by a $3.4 \mathrm{~kg}$ weight loss, with both targets superior to those achieved with monotherapy with either drug [4]. The reductions in systolic blood pressure and fasting and post-prandial glucose were also greater with the combination [4].

The same combination was also studied in a small group of obese adults without diabetes, similar effects on weight and systolic blood pressure observed. Magnetic resonance imaging assessments in that study indicated that the weight reduction was mostly due to adipose tissue reduction (subcutaneous and visceral adipose tissue equally) [5].

More recently, the AWARD-10 study [6] has shown a reduction in $\mathrm{HbA} 1 \mathrm{c}$ of up to $1.34 \%$ and a $3.1 \mathrm{~kg}$ weight loss upon the addition of dulaglutide $1.5 \mathrm{mg}$ weekly to the treatment regimen of patients being treated with an SGLT2 inhibitor (with or without metformin). There was also a significant reduction in SBP with dulaglutide $1.5 \mathrm{mg}$. Despite significant differences between these two studies, primarily simultaneous start in the DURATION-8 study and sequential use in the AWARD-10 study, both support a complementary effect of this combination in terms of reductions in $\mathrm{HbA1c}$, body weight and systolic blood pressure.

A post hoc analysis of the CANVAS study, which included 95 patients taking a GLP-1 receptor agonist $(74 \%$ exenatide and $26 \%$ liraglutide), showed that with canagliflozin $300 \mathrm{mg}$ daily there was a further drop in systolic blood pressure $(8.0 \mathrm{mmHg})$ and a further weight loss (3.2\%) over 18 weeks [7].

A single case report of treatment with the combination of canagliflozin and liraglutide resulting in the discontinuation of insulin therapy combined with a weight loss from 112 to $100 \mathrm{~kg}$ included a retrospective analysis of 15 subjects utilizing this combination [8]. HbA1c 
Table 1 Summary of results of prospective and observational studies examining the effects of the combination of sodium glucose cotransporter-2 inhibitors and glucagon-like peptide 1 receptor agonists on glycated hemoglobin, body weight and systolic blood pressure

\begin{tabular}{|c|c|c|c|c|c|}
\hline $\begin{array}{l}\text { Study } \\
\text { characteristics }\end{array}$ & 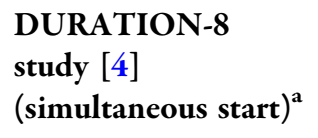 & $\begin{array}{l}\text { AWARD-10 } \\
\text { study [6] } \\
\text { (sequential use) }^{\text {b }}\end{array}$ & $\begin{array}{l}\text { Goncalves and Bell } \\
{[10](\text { simultaneous }} \\
\text { start })^{\mathrm{c}}\end{array}$ & $\begin{array}{l}\text { Goncalves and } \\
\text { Bell [10] } \\
\text { (sequential use) }^{c}\end{array}$ & $\begin{array}{l}\text { Saroka et al. } \\
\text { [9] (sequential } \\
\text { use) }\end{array}$ \\
\hline $\begin{array}{l}\text { Duration of } \\
\text { DM (years) }\end{array}$ & 7.6 & 9.2 & 11 & 9.3 & 13.8 \\
\hline $\begin{array}{l}\text { Duration of } \\
\text { study } \\
\text { (weeks) }\end{array}$ & 28 & 24 & 62 & 76 & 45 \\
\hline $\begin{array}{l}\text { Number of } \\
\text { patients }\end{array}$ & $\begin{array}{l}231 \text { (on } \\
\text { combination) }\end{array}$ & 142 & 33 & 46 & 75 \\
\hline $\begin{array}{l}\text { HbAlc } \\
\qquad \text { (initial) (\%) }\end{array}$ & 9.3 & 8.0 & 9.1 & 8.5 & 7.9 \\
\hline $\begin{array}{l}\text { HbAlc change } \\
(\%)\end{array}$ & -2.0 & -1.34 & -2.0 & -0.9 & -0.47 \\
\hline $\begin{array}{l}\text { Weight change } \\
(\mathrm{kg})\end{array}$ & -3.4 & -3.1 & -10 & -4 & -5.45 \\
\hline \multirow{2}{*}{$\begin{array}{l}\text { SBP change } \\
\qquad(\mathrm{mmHg})\end{array}$} & -4.2 & -4.5 & -13 & -7 & -4 \\
\hline & Prospective studies & & Observational studies & & \\
\hline
\end{tabular}

Drugs were initiated simultaneously or sequentially. In the latter case, with the sodium glucose cotransporter-2 (SGLT2) inhibitor administered first, followed by the glucagon-like peptide 1 (GLP-1) receptor agonist, or vice versa

$D M$ Diabetes mellitus, $H b A 1 c$ glycated hemoglobin, $S B P$ systolic blood pressure

${ }^{a}$ Exenatide LAR and dapagliflozin

${ }^{b}$ Dulaglutide $1.5 \mathrm{mg}$ data presented (added to an SGLT2 inhibitor)

c SGLT2 inhibitor added to liraglutide or started simultaneously

${ }^{\mathrm{d}}$ Canagliflozin added to GLP-1 receptor agonist, canagliflozin $300 \mathrm{mg}$ data presented

in this group dropped from $9.1 \%$ to $7.0 \%$, and mean body weight was reduced from 113 to $108 \mathrm{~kg}$, which is similar to the results obtained in the prospective study of dapagliflozin and exenatide [4]. Another retrospective study on subjects who had been on a GLP-1 receptor agonist for at least 1 year showed that the addition of canagliflozin to the therapeutic regimen resulted not only in a further small decrease in the HbA1c $(0.39 \%)$ but also in a further $4.6 \mathrm{~kg}$ weight loss [9].

The striking outcomes of these prospective and retrospective studies with these drugs stimulated the performance of a real world retrospective study utilizing computerized records in a single large endocrine practice (Table 1). Because there was a 3-year gap between the availability of liraglutide and that of the first SGLT2 inhibitor (canagliflozin) the study was divided into those who received sequential therapy $(n=46)$ and those who received simultaneous therapy $(n=33)$ [10]. In the sequential group, HbA1c dropped from $8.9 \%$ to $7.6 \%$, while in the simultaneous group the HbA1c dropped from $9.1 \%$ to $7.1 \%$. The group treated sequentially was on liraglutide for a 
median of 141 weeks when the SGLT2 inhibitor was added to the therapy, which explains the lower total $\mathrm{HbA1c}$ reduction in that group compared to that of the simultaneous start group. In the sequential group, liraglutide significantly reduced body weight from 111 to $105 \mathrm{~kg}$ and when the SGLT2 inhibitor was added there was a further decrease to $101 \mathrm{~kg}$. Total weight loss was very similar in the simultaneous group where there was also a weight loss of $10 \mathrm{~kg}$ (116-106 kg). The data suggested that there was a plateauing of the weight effect after about 1 year, since the weight loss was similar at both 62 and 217 weeks. In addition, in the sequential group systolic blood pressure dropped by $6 \mathrm{mmHg}$ with liraglutide and by a further $7 \mathrm{mmHg}$ with the addition of canagliflozin, while in the simultaneous group systolic blood pressure dropped by $13 \mathrm{~mm} \mathrm{Hg}$. There were no significant change in diastolic blood pressure [10]. In contrast to the symbiotic effects on HbA1c, body weight and systolic blood pressure, the beneficial effect of liraglutide on total cholesterol, low-density lipoprotein (LDL) cholesterol and non-high-density lipoprotein (HDL) cholesterol was nullified by the addition of an SGLT2 inhibitor [10]. Possibly because of a rapid improvement in glycemic control in the simultaneous group, but not the sequential group, there was a decrease in triglycerides and non-HDL cholesterol without a change in total or LDL cholesterol [10]. With decreases in HbA1c, body weight and systolic blood pressure as well as a drop in non-HDL cholesterol and triglycerides, the combination of a GLP-1 receptor agonist and a SGLT2 inhibitor should result in at least a decrease in cardiac risk and potentially a decrease in cardiac events.

\section{DISCUSSION}

To date positive cardiovascular outcomes have only been reported with daily liraglutide and weekly semaglutide, while an outcome study with dulaglutide is in progress [11-13]. In a safety study, lixisenatide was shown to have cardiac safety without an improvement in cardiac events, cardiac mortality or overall mortality [14]. In another study, once-weekly exenatide was shown to be non-inferior to placebo with respect to safety, but there were no significant decreases in myocardial infarction, stroke or hospitalization for heart failure; total and cardiovascular mortality were non-significantly decreased by 14 and $12 \%$, respectively [15].

Two of the four currently available SGLT2 inhibitors (empagliflozin and canagliflozin) are associated with decreased cardiovascular mortality and a decreased risk of admission to hospital with heart failure and all-cause mortality without a decrease in myocardial infarction or stroke $[16,17]$. In addition, a large retrospective international database study has shown decreases in cardiovascular events, all-cause mortality and hospitalization for heart failure in patients receiving dapagliflozin [18, 19]. Prospective studies with the GLP-1 receptor agonist liraglutide once-daily and the GLP-1 receptor agonist semaglutide once-weekly have shown decreases in non-fatal myocardial infarction, non-fatal stroke and cardiovascular and total mortality, without a decrease in admission to hospital with heart failure $[11,12]$. These GLP-1 receptor agonists are postulated to improve myocardial function through their capacity to decrease inflammation, improve endothelial function and decelerate atheroma formation [20]. GLP-1 agonists therefore have the potential to synergistically decrease major adverse cardiovascular cardiac events, cardiac mortality and total mortality when utilized in combination with SGLT-2 inhibitors.

SGLT2 inhibitors and GLP-1 receptor agonists have potentially complementary effects on renal function. Once-daily liraglutide $(1.8 \mathrm{mg})$ and once-daily empagliflozin (10 or $25 \mathrm{mg}$ ) were found to reduce incident or worsening diabetic nephropathy by $22 \%$ over 3.8 years and by $39 \%$ over 3.1 years, respectively [21, 22]. SGLT2 inhibitors and, to a lesser extent, GLP-1 receptor agonists, decrease renal proximal tubular sodium resorption. Sensing of the increased urine sodium by the macula densa results in decreased activity of the renin-angiotensin-aldosterone system. It also activates tubuloglomerular feedback, thereby increasing glomerular afferent arteriole resistance, which 
in turn leads to decreased intraglomerular pressure and decreased glomerular hyperfiltration, resulting in decreased proteinuria and a deceleration in the decline in renal function [23]. Reabsorption of sodium ions by the proximal tubule accounts for most of the kidney's workload; therefore, if in addition to a decreased sodium reabsorption and renal workload with an SGLT2 inhibition, there is also a change in metabolism from the use of glucose and free fatty acids as a substrate to the use of ketone bodies, there would be a further decrease in renal workload and preservation of renal function (see below). In addition, lowering of HbA1c, blood pressure, body weight and uric acid levels could play at least a partial role in the deceleration of renal decline.

Therefore, it can be concluded that the decreases in cardiac and total mortality seen with $\mathrm{SGLT}_{2}$ inhibitors is a class effect and probably only due to a decreased incidence and frequency of heart failure. The potential causes for this decrease in heart failure are protean, but a decrease in weight and blood pressure causing a decrease in the preload and afterload of the myocardium are likely hemodynamic candidates. However, the ability of SGLT2 inhibitors to shift metabolism away from the utilization of carbohydrate and free fatty acids to the utilization of ketone bodies derived from the breakdown of fat is an attractive hypothesis, and in our opinion a more likely explanation $[24,25]$. Ketone bodies are likely to be avidly utilized by the myocardium and kidney, resulting in decreases in both cardiac and renal workload. Thus, the beneficial cardiovascular effect of SGLT2 inhibitors are most likely to be through a decreased cardiac workload, leading to improvement in existing heart failure, prevention of "denovo" heart failure and decreased cardiac and total mortality.

The effect of GLP-1 receptor agonists in cardiovascular events is far more complex and clearly not due to a decrease in heart failure. In a study utilizing GLP-1 receptor agonists in patients hospitalized for heart failure with reduced left ventricular ejection fraction, the use of liraglutide did not lead to a greater posthospitalization clinical stability [26]. The cardioprotection provided by GLP-1 receptor agonists is most likely due to direct and indirect actions in multiple organs. In the heart itself, GLP-1 receptors are expressed on both the myocardiocyte and the vascular endothelium. Also, activation of receptors on monocytes, macrophages and lymphocytes will likely result in improved function, leading to decreased inflammation, improved endothelial function, a decrease in the formation of foam cells and increased stability of atheromatous plaques [20, 27-31]. Therefore, the proposed cardioprotective mechanisms of SGLT2 inhibitors and GLP-1 receptor agonists are likely to be complementary. Theoretically, the combined cardiac and renal effect of the SGLT-2 inhibitor and the GLP-1 receptor agonist could be decreased by lowered hepatic ketone production, which is dependent on glucagon activity that will be acutely suppressed by GLP-1 receptor agonists. However, chronic treatment, at least with liraglutide, is associated with a decrease or even a loss of glucagon suppression, which may negate this effect [32].

Despite beneficial effects on cardiovascular mortality noted in the EMPA-REG OUTCOME [16] and CANVAS [17], non-fatal stroke increased by $30 \%$ with empagliflozin and amputations increased by $97 \%$ with canagliflozin. Ketoacidosis has been reported with all SGLT2 inhibitors, although its risk may be attenuated by combining it with a GLP-1 receptor agonist. Both drug classes have been associated with acute renal failure, possibly due to fluid contraction, and the entire incretin-mimetic class has been associated with pancreatitis. The most common side effects, however, are gastrointestinal and genitourinary, which tend to improve over time [33].

In conclusion, the SGLT2 inhibitor and GLP1 receptor agonist combination has additive effects on glycemic control without the inconvenience and dangers of hypoglycemia. There are also synergistic effects on weight loss and blood pressure, potentially leading to lower cardiovascular events, heart failure, cardiovascular and total mortality, as well as a deceleration of renal function. However, if increased cardiac and renal consumption of ketone bodies is indeed the reason for improved outcomes with SGLT2 inhibitors, then the combination 
may negate the effects of SGLT2 inhibitors on cardiac and renal workload and decrease the cardiorenal benefits. Ultimately, only a cardiovascular and renal outcomes trial with the combination would provide an answer to this hypothesis.

Despite the beneficial and symbiotic effects of a combined therapeutic regimen consisting of a SGLT-2 receptor inhibitor and a GLP-1 agonist, this combination is not being widely utilized. Cost and formulary barriers are the probable reason for this, and in the absence of more prospective studies, third party payers are unlikely "to foot the bill." So why have these studies not been performed? The likeliest explanation is the reluctance of pharmaceutical companies to study their drugs in combination with a non-generic drug for which they do not have a patent. One of the prospective randomized studies was with dapagliflozin and exenatide, and notably the patents of both drugs are held by the same company [4]. In addition, there have been no prospective cardiovascular or renal outcomes trials with any GLP-1 receptor agonist/SGLT2 inhibitor combination. The reluctance to prospectively study this combination needs to be overcome to generate more conclusive data, so that it will be proven once and for all that this synergistic "Cadillac Combination" is effective and that it can be utilized at the earliest possible time in the course of type 2 diabetes.

\section{ACKNOWLEDGEMENTS}

Funding. No funding or sponsorship was received for this study or the article processing charges.

Authorship. All named authors meet the International Committee of Medical Journal Editors (ICMJE) criteria for authorship for this article, take responsibility for the integrity of the work as a whole, and have given their approval for this version to be published.

Disclosures. Edison Goncalves is on the speaker's bureau of Novo-Nordisk and Janssen
Pharmaceuticals. David S.H. Bell is on the Speaker's bureau of Novo-Nordisk, AstraZeneca and Janssen Pharmaceuticals.

Compliance with Ethics Guidelines. This article is based on previously conducted studies and does not contain any studies with human participants or animals performed by any of the authors.

Open Access. This article is distributed under the terms of the Creative Commons Attribution-NonCommercial 4.0 International License (http://creativecommons.org/licenses/ by-nc/4.0/), which permits any noncommercial use, distribution, and reproduction in any medium, provided you give appropriate credit to the original author(s) and the source, provide a link to the Creative Commons license, and indicate if changes were made.

\section{REFERENCES}

1. Pathak RD, Schroeder EB, Seaquist ER, Zeng C, Lafata JE, Thomas A, et al. Severe hypoglycemia requiring medical intervention in a large cohort of adults with diabetes receiving care in U.S. integrated health care delivery systems: 2005-2011. Diabetes Care. 2016;39(3):363-70.

2. Bays HE, Gonzalez-Campoy JM, Bray GA, Kitabchi $\mathrm{AE}$, Bergman DA, Schorr AB, et al. Pathogenic potential of adipose tissue and metabolic consequences of adipocyte hypertrophy and increased visceral adiposity. Expert Rev Cardiovasc Ther. 2008;6(3):343-68.

3. Matsuzawa Y. The role of fat topology in the risk of disease. Int J Obes (Lond). 2008;32[Suppl 7]:S83-92.

4. Frias JP, Guja C, Hardy E, Ahmed A, Dong F, Ohman $\mathrm{P}$, et al. Exenatide once weekly plus dapagliflozin once daily versus exenatide or dapagliflozin alone in patients with type 2 diabetes inadequately controlled with metformin monotherapy (DURATION8): a 28 week, multicentre, double-blind, phase 3 , randomised controlled trial. Lancet Diabetes Endocrinol. 2016;4(12):1004-16.

5. Lundkvist P, Pereira MJ, Katsogiannos P, Sjostrom CD, Johnsson E, Eriksson JW. Dapagliflozin once daily plus exenatide once weekly in obese adults without diabetes: sustained reductions in body 
weight, glycaemia and blood pressure over 1 year. Diabetes Obes Metab. 2017;19(9):1276-88.

6. Ludvik B, Frias JP, Tinahones FJ, Wainstein J, Jiang $\mathrm{H}$, Robertson KE, et al. Dulaglutide as add-on therapy to SGLT2 inhibitors in patients with inadequately controlled type 2 diabetes (AWARD-10): a 24-week, randomised, double-blind, placebo-controlled trial. Lancet Diabetes Endocrinol. 2018. doi: https://doi.org/10.1016/S2213-8587(18)30023-8

7. Fulcher G, Matthews DR, Perkovic V, de Zeeuw D, Mahaffey KW, Mathieu C, et al. Efficacy and safety of canagliflozin when used in conjunction with incretin-mimetic therapy in patients with type 2 diabetes. Diabetes Obes Metab. 2016;18(1):82-91.

8. Bell DS. The potent synergistic effects of the combination of liraglutide and canagliflozin on glycemic control and weight loss. Am J Case Rep. 2014;15:152-4.

9. Saroka RM, Kane MP, Busch RS, Watsky J, Hamilton RA. SGLT-2 inhibitor therapy added to GLP-1 agonist therapy in the management of T2DM. Endocr Pract. 2015;21(12):1315-22.

10. Goncalves E, Bell DSH. Glucagon-like peptide-1 receptor agonists and sodium-glucose co-transporter-2 inhibitors: sequential or simultaneous start? Diabetes Obes Metab. 2017;19(6):909-11.

11. Marso SP, Daniels GH, Brown-Frandsen K, Kristensen P, Mann JF, Nauck MA, et al. Liraglutide and cardiovascular outcomes in type 2 diabetes. New Engl J Med. 2016;375(4):311-22.

12. Marso SP, Bain SC, Consoli A, Eliaschewitz FG, Jodar E, Leiter LA, et al. Semaglutide and cardiovascular outcomes in patients with type 2 diabetes. New Engl J Med. 2016;375(19):1834-44.

13. Gerstein HC, Colhoun HM, Dagenais GR, Diaz R, Lakshmanan M, Pais P, et al. Design and baseline characteristics of participants in the researching cardiovascular events with a weekly incretin in diabetes (REWIND) trial on the cardiovascular effects of dulaglutide. Diabetes Obes Metab. 2018;20(1):42-9

14. Pfeffer MA, Claggett B, Diaz R, Dickstein K, Gerstein $\mathrm{HC}$, Kober LV, et al. Lixisenatide in patients with type 2 diabetes and acute coronary syndrome. New Engl J Med. 2015;373(23):2247-57.

15. Holman RR, Bethel MA, Mentz RJ, Thompson VP, Lokhnygina Y, Buse JB, et al. Effects of once-weekly exenatide on cardiovascular outcomes in type 2 diabetes. New Engl J Med. 2017;377(13):1228-39.

16. Zinman B, Wanner C, Lachin JM, Fitchett D, Bluhmki E, Hantel S, et al. Empagliflozin, cardiovascular outcomes, and mortality in type 2 diabetes. New Engl J Med. 2015;373(22):2117-28.

17. Neal B, Perkovic V, Mahaffey KW, de Zeeuw D, Fulcher G, Erondu N, et al. Canagliflozin and cardiovascular and renal events in type 2 diabetes. New Engl J Med. 2017;377(7):644-57.

18. Persson F, Nystrom T, Jorgensen ME, Carstensen B, Gulseth HL, Thuresson M, et al. Dapagliflozin is associated with lower risk of cardiovascular events and all-cause mortality in people with type 2 diabetes (CVD-REAL Nordic) when compared with dipeptidyl peptidase-4 inhibitor therapy: a multinational observational study. Diabetes Obes Metab. 2018;20(2):344-51.

19. Toulis KA, Willis BH, Marshall T, Kumarendran B, Gokhale K, Ghosh S, et al. All-cause mortality in patients with diabetes under treatment with dapagliflozin: a population-based, open-cohort study in the health improvement network database. J Clin Endocrinol Metab. 2017;102(5):1719-25.

20. Arakawa M, Mita T, Azuma K, Ebato C, Goto H, Nomiyama T, et al. Inhibition of monocyte adhesion to endothelial cells and attenuation of atherosclerotic lesion by a glucagon-like peptide-1 receptor agonist, exendin-4. Diabetes. 2010;59(4):1030-7.

21. Mann JFE, Orsted DD, Brown-Frandsen K, Marso SP, Poulter NR, Rasmussen S, et al. Liraglutide and renal outcomes in type 2 diabetes. New Engl J Med. 2017;377(9):839-48.

22. Wanner C, Inzucchi SE, Lachin JM, Fitchett D, von Eynatten M, Mattheus M, et al. Empagliflozin and progression of kidney disease in type 2 diabetes. New Engl J Med. 2016;375(4):323-34.

23. Cherney DZ, Perkins BA, Soleymanlou N, Maione M, Lai V, Lee A, et al. Renal hemodynamic effect of sodium-glucose cotransporter 2 inhibition in patients with type 1 diabetes mellitus. Circulation. 2014;129(5):587-97.

24. Mudaliar S, Alloju S, Henry RR. Can a shift in fuel energetics explain the beneficial cardiorenal outcomes in the EMPA-REG OUTCOME Study? A unifying hypothesis. Diabetes Care. 2016;39(7):1115-22.

25. Ferrannini E, Mark M, Mayoux E. CV protection in the EMPA-REG OUTCOME trial: a "thrifty substrate" hypothesis. Diabetes Care. 2016;39(7):1108-14.

26. Margulies KB, Hernandez AF, Redfield MM, Givertz MM, Oliveira GH, Cole R, et al. Effects of liraglutide on clinical stability among patients with advanced 
heart failure and reduced ejection fraction: a randomized clinical trial. JAMA. 2016;316(5):500-8.

27. Liu H, Dear AE, Knudsen LB, Simpson RW. A longacting glucagon-like peptide- 1 analogue attenuates induction of plasminogen activator inhibitor type-1 and vascular adhesion molecules. J Endocrinol. 2009;201(1):59-66.

28. Hattori Y, Jojima T, Tomizawa A, Satoh H, Hattori S, Kasai K, et al. A glucagon-like peptide-1 (GLP-1) analogue, liraglutide, upregulates nitric oxide production and exerts anti-inflammatory action in endothelial cells. Diabetologia. 2010;53(10):2256-63.

29. Gaspari T, Liu H, Welungoda I, Hu Y, Widdop RE, Knudsen LB, et al. A GLP-1 receptor agonist liraglutide inhibits endothelial cell dysfunction and vascular adhesion molecule expression in an ApoE-/- mouse model. Diabetes Vasc Dis Res. 2011;8(2):117-24.
30. Nagashima M, Watanabe T, Terasaki M, Tomoyasu M, Nohtomi K, Kim-Kaneyama J, et al. Native incretins prevent the development of atherosclerotic lesions in apolipoprotein $\mathrm{E}$ knockout mice. Diabetologia. 2011;54(10):2649-59.

31. Tanaka M, Matsuo Y, Yamakage H, Masuda S, Terada Y, Muranaka K, et al. Differential effects of GLP1 receptor agonist on foam cell formation in monocytes between non-obese and obese subjects. Metab Clin Exp. 2016;65(2):1-11.

32. Kramer CK, Zinman B, Choi H, Connelly PW, Retnakaran R. The impact of chronic liraglutide therapy on glucagon secretion in type 2 diabetes: insight from the LIBRA trial. J Clin Endocrinol Metab. 2015;100(10):3702-9.

33. Faillie JL. Pharmacological aspects of the safety of gliflozins. Pharmacol Res. 2017;118:71-81. 